\title{
Advanced Reservoir Characterization in the Antelope Shale to Establish the Viability of C02 Enhanced Oil Recovery in California's Monterey Formation Siliceous Shales
}

\author{
Quarterly Report \\ July 1 - September 30, 1997 \\ By: \\ Michael F. Morea
}

Work Performed Under Contract No.: DE-FC22-95BC14938

\author{
For \\ U.S. Department of Energy \\ Office of Fossil Energy \\ Federal Energy Technology Center \\ P.O. Box 880 \\ Morgantown, West Virginia 26507-0880 \\ By \\ Chevron USA Production Company (CPDN) \\ 5001 California Avenue \\ Bakersfield, California 93309
}




\section{Disclaimer}

This report was prepared as an account of work sponsored by an agency of the United States Government. Neither the United States Government nor any agency thereof, nor any of their employees, makes any warranty, express or implied, or assumes any legal liability or responsibility for the accuracy, completeness, or usefulness of any information, apparatus, product, or process disclosed, or represents that its use would not infringe privately owned rights. Reference herein to any specific commercial product, process, or service by trade

name, trademark, manufacturer, or otherwise does not necessarily constitute or imply its endorsement, recommendation, or favoring by the United States Government or any agency thereof. The views and opinions of authors expressed herein do not necessarily state or reflect those of the United States Government or any agency thereof. 
TITLE: ADVANCED RESERVOIR CHARACTERIZATION IN THE ANTELOPE SHALE TO ESTABLISH THE VIABILITY OF CO2 ENHANCED OIL RECOVERY IN CALIFORNIA'S MONTEREY FORMATION SILICEOUS SHALES

Cooperative Agreement No.: DE-FC22-95BC14938--08

Report No.: 14938r08

Date of Report: October 24, 1997

Reporting Period: July 1, 1997 - September 30, 1997

Government Award for Budget Period \# 1: \$2,334,048

Award Date: February 7, 1996

Anticipated Completion Date for Budget Period \# 1: June 11, 1998

DOE Project Manager: Jerry F. Casteel, National Petroleum Technology Office

Principal Investigator: Michael F. Morea

Contractor Name and Address: Chevron USA Production Company, P.O. Box 1392, Bakersfield, California 93302

\section{Objective}

The primary objective of this research is to conduct advanced reservoir characterization and modeling studies in the Antelope Shale reservoir. Characterization studies will be used to determine the technical feasibility of implementing a $\mathrm{CO}_{2}$ enhanced oil recovery project in the Antelope Shale in Buena Vista Hills Field. The Buena Vista Hills pilot $\mathrm{CO}_{2}$ project will demonstrate the economic viability and widespread applicability of $\mathrm{CO}_{2}$ flooding in fractured siliceous shale reservoirs of the San Joaquin Valley. The research consists of four primary work processes: Reservoir Matrix and Fluid Characterization; Fracture Characterization; Reservoir Modeling and Simulation; and $\mathrm{CO}_{2}$ Pilot Flood and Evaluation. Work done in these areas is subdivided into two phases or budget periods. The first phase of the project will focus on the application of a variety of advanced reservoir characterization techniques to determine the production characteristics of the Antelope Shale reservoir. Reservoir models based on the results of the characterization work will be used to evaluate how the reservoir will respond to secondary recovery and EOR processes. The second phase of the project will include the implementation and evaluation of an advanced enhanced oil recovery (EOR) pilot in the United Anticline (West Dome) of the Buena Vista Hills Field. 


\section{Summary of Technical Progress}

Outlined below is a status report on the tasks that were performed during the 3rd quarter of 1997. Overall the project remains on budget and on schedule. All core samples or analyses are from the 653Z-26B well unless stated otherwise.

\section{Task A. Characterize the Brown Shale and Antelope Shale}

\section{Task A.3. Perform Core Analysis}

\section{Task A.3.A. Wettability Testing - Laboratory}

All samples, except those from depths of 4288.2 and 4414.3 feet, have been miscibly cleaned and saturated with formation brine at Core Laboratories, Bakersfield. Samples from depths of 3989.2, 4315.6 and 4355.95 feet have undergone forced oil, spontaneous water and forced water drainage processes. The remaining samples, including 4288.2 and 4414.3 are deemed too tight for analysis.

Combined USBM/Amott wettability measurements were performed on core samples from 3989.2, 4315.6 and 4355.95 feet. The Amott wettability indices indicate that the samples were of mixed wettability (predominantly water-wet). USBM wettability indices indicate that the samples, with the exception of 4315.6 feet, were also water-wet. This particular sample exhibited a wettability index that is slightly oil wet. The above data will be used in the water injection and imbibition studies.

\section{Task A.3.G. Extracted Oil Geochemical Fingerprinting}

Dave Baskin of Chevron Petroleum Technology Co. (CPTC) continues working on the 25 core plug samples for oil extraction, along with produced oil samples from nearby wells. Comparing the extracted oil samples with the produced oils will help identify what zones in the Brown Shale and Antelope Shale are contributing to oil production. This task will be completed next quarter.

\section{Task A.3.H. Mineralogical Analysis}

Data needed to build the Buena Vista Hills siliceous shale mineral-model is nearing completion. The mineral model is being built to enhance estimates of porosity, oil saturation, lithology, and permeability, from log data. Core Laboratories, Bakersfield has completed their chemical analysis (Mineralog ${ }^{\circledR}$ ) portion of this task. CPTC expects their chemical analysis (ESTMIN) portion of this task to be completed next quarter.

Both geochemical techniques show the Brown and Antelope shales to be composed of biogenic silica (opal-ct), detritus (clay, quartz, feldspar and pyrite) and minor carbonate. The weight percentages of biogenic silica in the Brown Shale at Buena Vista Hills are higher than the typical clay-rich Brown Shale lithology found in other parts of the southern San Joaquin Valley.

\section{Task A.3.I. Mercury Porosimetry}

Mercury porosimetry analysis was performed by Core Laboratories, Bakersfield on 15 core samples in order to determine pore size distribution and help define hydraulic flow units. Siliceous shale samples have pore throat radii less than 0.50 microns while clayey sand samples have radii that can reach into the 2.5 to 10.0 micron range. Mercury saturations at 
2000 psi are less than $25 \%$ for siliceous shale, and range from 43 to $87 \%$ for clayey sand. This indicates, that by equating mercury saturation to oil saturation, the siliceous shale at Buena Vista Hills is not capable of having high oil saturations at reservoir conditions, whereas the clayey sand is capable of having high oil saturations. Thus most of the produced oil in the field may have come from the thin sands and infrequent open fractures in the Brown and Antelope shales. This possibility will continue to be studied as more data is compiled.

\section{Task A.3.J. NMR Scan of Core Plugs}

Core Laboratories, Bakersfield has completed nuclear magnetic resonance (NMR) measurements on 15 core plugs. NMR measurements were made before and after fluid extraction from the specific permeability core plugs in order to compare NMR log and core responses, and help create a log-core transform. The geometric mean of the NMR transverse relaxation times, T2, match fairly well with the NMR log, but NMR core plug porosity does not match routine core porosity or NMR log porosity. This needs to be investigated further.

\section{Task A.3.K. Rock Mechanics Analysis}

Rock mechanics analyses (compressibility, Poisson's ratio, and Young's modulus) have been completed by Core Laboratories, Dallas. This data will be used in the modeling and design of hydraulic fractures.

\section{Task A.3.0. Core Imaging}

Digital core image analysis has been completed by Core Laboratories, Houston. This is the first time this technique has been used on siliceous shale. Ultraviolet photographs of the entire 952 feet of core were digitized and computer analyzed for medium to very high fluorescence, and for very high fluorescence only. With this data we can quantify the siliceous shale, clay shale, sand and carbonate beds found in the core. The core image analysis will be displayed on a well log montage along with the routine core description and other data.

\section{Task A.4. Fracture Characterization}

\section{Task A.4.B. Crosswell Seismic}

TomoSeis is presently working on de-bugging their new software code so that it can be used in deviated wells such as the 653Z. Currently, their software requires that during processing both velocity images (tomograms) and reflection images that involve deviated wells be projected onto a 2-D imaging plane and then straightened to the vertical. Since all 4 profiles at Buena Vista Hills were shot with the source in a vertical well and the receivers in a deviated well (the 653Z well dips at about a 16 degree angle to the vertical), all 4 profiles suffer at least some degradation in quality due to the required projections. Plans call for reprocessing the crosswell data once TomoSeis completes their software modifications.

\section{Task A.4.K. Attenuation Imaging}

Jerry Harris of Stanford University is presently working on deriving a 3D velocity inversion using the crosswell seismic data. This $3 \mathrm{D}$ inversion is necessitated by the fact that well 
$653 \mathrm{Z}$ is deviated and all 4 crosswell data-sets suffer at least some degradation in quality due to the simplifications necessary to solve for velocity using $2 \mathrm{D}$ methods. Once the full $3 \mathrm{D}$ solution is derived, the data will be analyzed for attenuation effects, and an attempt will be made to relate attenuation to fracture density in the reservoir.

\section{Task A.4.D. High Resolution Structural Mapping}

During the third quarter, sixteen structure map grids covering the United Anticline were generated (using Z-Map+) for all mapped horizons within the Brown Shale and Upper Antelope Shale. Grid spacing was 100' in both the X and Y directions. The grids were then exported to Stratamodel where they will be used to form the framework for the 3D geologic model.

\section{Task A.4.E. Core Fracture Analysis}

$224 \mathrm{ft}$ of whole core taken over 30 years ago in well 32-26B (located about $3000 \mathrm{ft}$ WNW of well 653Z) was reviewed in September by Wayne Narr of CPTC for evidence of fractures. Because of its age, the core was extensively desiccated, and all fractures and many bedding plane surfaces were distended. No reliable fracture aperture information was available as a consequence of the desiccation. However, the core was otherwise well preserved, and induced mechanical breakage was minimal.

Two types of fractures were observed in the 32-26B core. First, sigmoidal fractures lined with clay. These were interpreted to be soft-sediment deformation features formed within a few meters of the sea floor shortly after burial of the sediments. Although they were open in the core in September, they are likely healed in the subsurface, and their open condition is a result of desiccation. They appear more likely to act as baffles to fluid flow than as conduits.

Second, joint-like, tectonic fractures which probably contribute to the productivity of the well. They appeared to be in greater abundance at deeper stratigraphic intervals. Their dips were nearly vertical, and their heights were relatively short ( 0.44 feet average). Fracture densities ranged from 0 to 12 fractures per 20 feet interval with the highest densities occurring in the Antelope Shale as compared to the Brown Shale.

Plans are underway to have the $653 \mathrm{Z}$ core characterized in a similar fashion in January, 1998 to help determine if the Antelope Shale fracture density increase has some lateral continuity. These fracture trends will then be incorporated into the 3D volume reservoir modeling.

\section{Task A.4.F. Core Microfracture Analysis}

Petrographic and confocal analysis of twelve thin sections has been completed by TerraTek. This study was designed to determine presence of micropermeability, microfractures, and microfracture orientation. The thin sections, which are representative of the shales found in the core, were analyzed by using transmitted light, epifluorescent light, and confocal microscopy techniques. In addition, examination of microfractures was performed on all samples, and measurements of fracture orientations were obtained from three oriented thin sections. 
All twelve samples are of similar lithology and can be characterized as silty, dolomitic, opaline mudstones. Matrix is composed of isotropic opal-ct with minor amounts of very finely crystalline dolomite dispersed throughout the sample. Detrital mineralogy is arkosic with minor carbonate rock fragments. Silt grains are angular and matrix supported, and coarser carbonate grains are predominantly composed of ferroan dolomite. Biotic grains are common in some intervals and likely include diatoms, sponge spicules, and various foraminifers.

Porosity exists in three generalized void forms: 1) matrix microporosity; 2) molds, and 3) fractures. Minute micropores represent the greatest void volume, but exhibit highly restricted pore-to-pore connectivity. Slight dissolution of matrix enhances microporosity in localized areas. Moldic pores are volumetrically significant at some depths, and connectivity of isolated moldic pores is dependent upon (dissolution-enhanced) porosity development in the enveloping matrix. In most fractured samples, both open (or reopened) and healed fractures are present. Effective fracture porosity is most commonly concentrated along older previously healed cracks. Healed fractures invariably contain dark clay, organic material, and pyrite, but may locally contain silica cement in the form of opal or chalcedony. In open or reopened fractures, apertures are typically narrow and most commonly range from <2microns to 40 microns. Three of the twelve thin sections samples are oriented with respect to north, and close examination of these microfractures reveals no distinct or repeatable fracture patterns.

\section{Task A.4.H. Regional Tectonic Synthesis}

Advanced Resources International (ARI) is nearing completion of their work on the regional tectonic synthesis of the southern San Joaquin basin. This has been a two part effort. Part I, "Synopsis of Previous Investigations," was completed earlier this year. Part II, "Structural Analysis and Natural Fracture Characterization," should be completed by the end of October, 1997.

ARI presents two preliminary findings. First, straight drainage features tend to be aligned and form regional geomorphic features oriented roughly $\mathrm{NE}$ and perpendicular to the folds in the study area. These features may represent fracture zones developed nearly parallel to the direction of greatest principal crustal stress in the region. Second, most of the straight escarpments (scarps) form NW-oriented alignments which parallel or sub-parallel the strike of the San Andreas Fault, and may represent the active fault systems in the region.

\section{Task A.5. Wireline Log Analysis}

\section{Task A.5.A. Complex Lithologic Analysis}

Stan Denoo of Schlumberger, Denver created three preliminary mineral models from logging suite combinations: model 1) Platform Express triple combo / Combinable Magnetic Resonance / Elemental Capture Sonde; model 2) Platform Express triple combo / Combinable Magnetic Resonance, and model 3) Platform Express triple combo only. The models consist primarily of five mineral components: opal-ct phase biogenic silica, detrital quartz sand, feldspar, carbonate, and clay. Final mineral models from logs will be created and the results will be evaluated when core mineralogy is completed in November 1997. 


\section{Task A.6. Characterize Flow Units \\ Task A.6.A. Define Hydraulic Flow Units}

Hydraulic flow units can be defined as reservoir volumes that share geologic and petrophysical fluid flow properties that are internally consistent and predictably different from other rock volumes. Reservoir characterization using flow unit rather than strict lithology correlation should yield a more accurate simulation model, particularly in complex, finely-laminated, mixed lithology reservoirs such as the Brown and Antelope shales. Integration of core analysis, log analysis, and fracture characterization to define flow units is underway at Core Laboratories, Bakersfield and will be completed next quarter.

\section{Task A.6.B. Develop Flow Unit Transform(s)}

Work is in progress at Core Laboratories, Bakersfield to develop an accurate log-flow unit transform that can utilize the existing log data in the field. This work is expected to be completed next quarter.

\section{Task A.7. Develop 3D Earth Model \\ Task A.7.B. Geostatistically Populate Model}

To explore relationships between Drill Stem Test (DST) permeability and the SP log at Buena Vista Hills, Chuck Magnani of CPTC reviewed fifty-five DST's and judged eleven to contain some formation permeability information. Seven of the DST's were judged to have valid formation permeabilities ranging from $0.01-1.8$ millidarcies (md), and four of the DST's were judged to have been somewhat influenced by borehole storage and transition effects, though still have formation permeability information (permeabilities ranging from $0.023-5.0 \mathrm{md}$ ).

After trying to establish a correlation of DST permeability to normalized SP in many ways (valid tests only, valid tests + transition \& storage tests, first/second/third order polynomials, logarithmic, exponential), the most physically realistic correlation, with a correlation coefficient $r=0.841$, is the one established for the case Vsh_SP $<=1.0$ / Valid Tests Only:

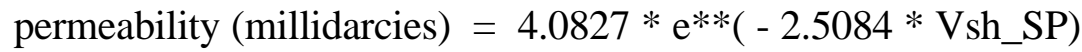

where Vsh_SP is the normalized SP log.

Thus, when Vsh_SP $=0$ (coarsest grained case), permeability $=4.08 \mathrm{md}$, and when Vsh_SP $=1$ (finest grained case), permeability $=0.33 \mathrm{md}$.

This correlation does not accommodate thin sands that have higher permeability. The correlation will be modified at the coarsest grained end to accommodate higher core permeabilities observed in core plugs taken in thin sands.

Also, Jack Hall of Z\&S Consultants, Houston is inverting old E-logs in three wells to create traces of earth resistivity. Combined with the porosity curves we have already generated using a correlation of porosity to SP, we will calculate initial oil saturation in the three wells. The 1996 well 653Z, with modern logs and core, will be used to establish the appropriate petrophysical parameters (a, $\mathrm{m}$, and $\mathrm{n}$ ) to use in an Archie saturation equation. 
If the results are judged to be valid, a larger set of wells will be chosen to process for initial oil saturation.

Lastly, core data and log curves from wells on United and Honolulu anticlines were prepared for use in neural net training of SP and resistivity curves in wells without core to derive sandiness and shaliness proxy curves. These curves will then be used to guide marker-controlled interval facies analysis (based on curve pattern recognition) prior to populating the reservoir volume with PKS and lithology realizations.

\section{Task A.7.C. Visualize Reservoir Property Distribution}

An initial, proof-of-concept, 200,000 cell, gridded volume was created for a portion of the Upper Antelope (P Pt. to P1B interval) on the United Anticline. The volume was populated with porosity derived from SP curves using a previously derived SP - porosity transform. This property-populated volume, displayed in Gocad, was a successful test of a work flow for generating facies-conditioned reservoir property realizations. Efforts are now being directed at improving the quality and content of the database to be used as a front end to this process.

\section{Task B. Preliminary Preparation for CO2 Injection}

\section{Task B.2. Initiate Fluid Characterization and Lab Displacement Tests}

Task B.2.A. Phase Behavior on CO2 - Oil Systems

While the ambient condition relative permeability tests have yielded good results, the reservoir condition tests (two completed) seem to be having problems. One of the reservoir condition tests yielded the same relative permeability curves as the ambient test of the same plug. Also, the other sample appeared to plug up during the reservoir condition test, possibly due to a problem with the crude oil. Moreover, there are difficulties with closing the material balance using Karl-Fischer titration of the effluent solvents. There is an unknown source of additional water that cannot be accounted for in the solvents. Perhaps it is water in the crude oil. Frank Ene of Core Laboratories, Bakersfield is doing a few simple tests to investigate the problem.

All seven of the ambient condition relative permeability tests are finished. However, it is not worthwhile to perform the reservoir condition tests. There are too many uncertainties with the procedures and the crude oil is likely to cause more plugging problems. Therefore we will not proceed with the reservoir condition tests. Instead some sophisticated mercury injection tests are being performed. The results can be compared to the ambient oil/water tests and they can be used to validate the other mercury intrusion tests that have already been performed by Core Laboratories. Thus, we can get a better understanding on what were the initial water saturations.

\section{Task B.2.B. Perform CO2 Corefloods at Reservoir Conditions}

Dengen Zhou, Russ Boyer and Rod Ulrich of CPTC have constructed the mixed lithology composite sample and core holder. The composite core consists of a synthetic high permeability channel adjacent to siliceous shale. The synthetic high permeability channel was machined from a Berea core sample. The siliceous shale portion of the core is from the slabbed whole core. Construction of the "mixed lithology" core was required because 
plug samples containing both sands and siliceous shale lithologies consistently broke in the core plug sampling process. The "mixed lithology" core has been restored to reservoir conditions and oil recovery experiments are underway.

A sandstone lithology sample also has been constructed. Restoration to reservoir conditions is underway.

Task B.2.C. Perform Water Injection and Imbibition Studies

Ray Tang and Dale Beeson of CPTC and Tom Zalan have coordinated on the porosity/permeability modeling process to be used in the 3D Earth Model. Questions remain on whether the low range permeabilities are being captured. Ray Tang and Ed Dezabala (CPTC) continue evaluating the special core analysis data to be used in determining irreducible water saturation distribution and relative permeability relations.

\section{Task D. Technology Transfer}

\section{Oral Presentations:}

Fargo, D., Sept. 1997, Advanced Coring and Wellsite Case Study of Chevron/DOE Well 653Z-26B, Core Technology Meeting, Anchorage, Alaska.

Langan, R. T., July, 1997, Crosswell Reflection Imaging in the San Joaquin Valley: Buena Vista Hills, Society of Exploration Geophysicists, Development and Production Forum, Vail, Colorado.

The following abstracts have been submitted to the 1998 AAPG Annual Convention, Salt Lake City, Utah:

Beeson, D. C., Tang, R. W., Thorne, J. A., Julander, D. R., Morea, M. F., and Zalan, T. A., Advanced Reservoir Characterization of the Siliceous Shale, Buena Vista Hills, California. Part 2: Reservoir Modeling and Visualization.

Britton, A. W., and Morea, M. F., Acoustic Anisotropy Measurements in the Siliceous Shale, 653Z-26B Well, Buena Vista Hills Field, California.

Campagna, D. J., Regional Tectonic Synthesis of the Southern San Joaquin Valley.

Morea, M. F., Zalan, T. A., Julander, D. R., and Britton, A. W., Advanced Reservoir Characterization of the Siliceous Shale, Buena Vista Hills, California. Part I: Integration of Geological, Geochemical, and Petrophysical Data.

The following abstract has been submitted to the 1998 SPWLA Annual Convention, Keystone, Colorado:

Zalan, T. A., Morea, M. F., Julander, D. R., and Denoo, S. A., Applying Integrated Formation Evaluation to Advanced Reservoir Characterization in California's Monterey Formation Siliceous Shales. 